\title{
Reply to McKibbin and Quiggin
}

\section{Alex Robson}

I find little in the contributions of Professors Quiggin and McKibbin that addresses my concerns regarding the benefits (or lack thereof) to Australia of reducing our greenhouse-gas emissions.

Quiggin's chief cavil seems to be with some of the (allegedly) misleading statements made by the Prime Minister and the Task Group regarding the costs of reducing Australia's emissions by 20 per cent (relative to 1990 levels). I do not find Quiggin's remarks on this matter very persuasive. He claims that 'the most ambitious target currently under discussion is that of the EU: that developed countries should commit to a reduction of 20 per cent relative to 1990 levels'. This claim is, however, incorrect. The ALP National Platform ${ }^{1}$ states that: 'Labor will cut Australia's greenhouse gas emissions by 60 per cent on year 2000 levels by $2050 . '$

This is far more ambitious than the EU plan. In 2000, Australia's total emissions were around 550 megatonnes in $\mathrm{CO}_{2}$ equivalent terms. So Labor's policy translates into a target of 330 megatonnes of emissions by 2050. In the absence of any policy interventions, 'business-as-usual' greenhouse emissions are projected to grow strongly. Indeed, the Australian Greenhouse Office's best-case scenario projects that even with abatement measures in place, total emissions will be around 700 megatonnes by 2020 - more than double Labor's 2050 target. The analysis suggests (but does not predict) that by 2050 total emissions will easily exceed 1000 megatonnes. In other words, achieving Labor's target could be equivalent to eliminating more than 100 per cent of current activities that use fossil fuels! The claims made by the Prime Minister and the Task Group are therefore quite modest.

Professor McKibbin is correct to point out that a policy of emissions abatement at any cost (which is precisely what Labor's policy is) lacks credibility, and that the Prime Ministerial Task Group approach suffers from the same problem.

Unfortunately, the McKibbin-Wilcoxen 'Blueprint' approach is also prone to similar problems. Under the Blueprint, the government will implement a price cap in the short-term permit market 'in case there are not enough long-term permits around in any year'. The government undertakes this resetting of the safety valve every five years. But how will anyone know whether there are 'enough' long-term permits? Nobody even seems to be able to answer that question today. The Blueprint idea seems to be that governments will observe

${ }^{1}$ 〈http://www.alp.org.au/platform/chapter_09.php\#9climate_change〉 This Platform was adopted at the ALP National Conference on 27-9 April 2007. 
movements in the long-term permit price and make a judgment as to whether the price is too high or low. Hopefully, this judgment will be informed by a rigorous cost-benefit analysis that will make some assessment of current costs as reflected in the long-term permit price. But, as my article points out, there has to date been no comprehensive, credible cost-benefit analysis of emissions reductions for Australia. So why should we expect that such an analysis would be done every five years? Given the current state of the policy debate, any commitment to do this is severely lacking in credibility. 